\title{
Single Level Lumbar Disk Herniation: Conventional Discectomy versus Interbody Fusion with Bilateral Pedicular Fixation
}

\author{
Ahmed K. Abdelaziz*, Ehab Abdel Haleem, Ahmed M. Ali, Omar El Falaky, Helmy Abdel Haleem \\ Department of Neurosurgery, Cairo University, Giza, Egypt
}

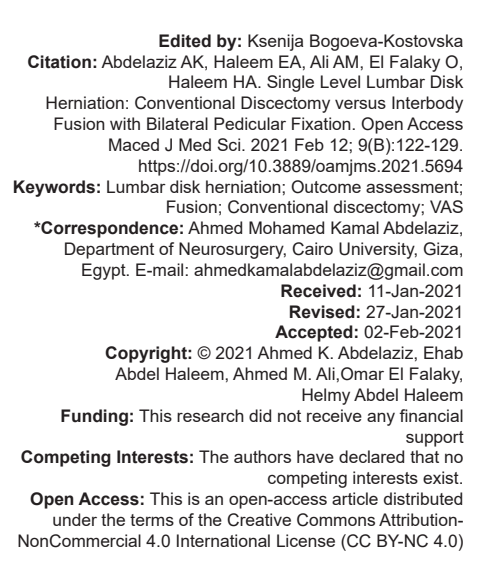

\section{Introduction}

Lumbar disk herniation (LDH) is one of the most frequently diagnosed causes of low back pain (LBP) and is a common cause of radiculopathy [1] that can result from general wear and tear [2]. Epidemiological evidence indicates that axial torque/twist combined with repetitive motions of flexion-extension can result in LDH [3].

Lumbar discectomy is a common and widely accepted operation for lumbar disk herniation in most industrialized countries with success rates of over $90 \%$, although other authors demonstrated that long-term results have been less positive, with success rates of $40-79 \%$. Several authors indicated that residual back pain and recurrent disk herniation were important factors affecting long-term results of discectomy alone [4].

Methods of spinal arthrodesis continue to evolve, in efforts to treatback pain. The latest techniques include approaching from anterior, posterior, lateral, and posterolateral. Interbody fusion techniques have been developed to provide solid fixation of spinal segments while maintaining load-bearing capacity and proper disk height. Reconstructing the anterior column after disk removal is important because, as well known, $80 \%$ of the compressive, torsion, and shear forces are transmitted through the anterior column [5].

Different techniques and technologies are now available for fusion, and each operative technique has its inherent benefits and disadvantages [5].

Introduced by Cloward more than 50 years ago, posterior lumbar interbody fusion (PLIF) represented a significant evolution in the operative treatment of pathological spinal disorders. Many variations of interbody fusions have since been described including anterior lumbar interbody fusion and transforaminal lumbar interbody fusion (TLIF) [6].

Our concern here is whether spinal fusion can settle these problems and attain a better and more durable outcome than discectomy alone [4].

This is a prospective study to compare between the conventional discectomy and the discectomy with interbody fusion and bilateral pedicular screw fixation in the management of single level lumbar disk herniation. 


\section{Materials and Methods}

\section{Study design}

In this prospective controlled, non-randomized, comparative, and clinical study, we included 50 cases operated upon during the period from October 2018 till June 2019 of which 25 patients were operated by conventional discectomy and the other 25 were operated upon by interbody fusion with bilateral pedicular fixation. We enrolled patients older than 15 years of age who were diagnosed with lumbar disk herniation and met the inclusion criteria (Table 1). Patient assessment was conducted by a neurosurgical specialist in the form of history taking, complete clinical examination, and radiological workup (dynamic radiographic views and MRI of the lumbar spine). The LDH diagnosis was based on the presence of signs and symptoms of radiculopathy as well as the MRI findings of a disk herniation in one level.

Table 1: Inclusion and exclusion criteria

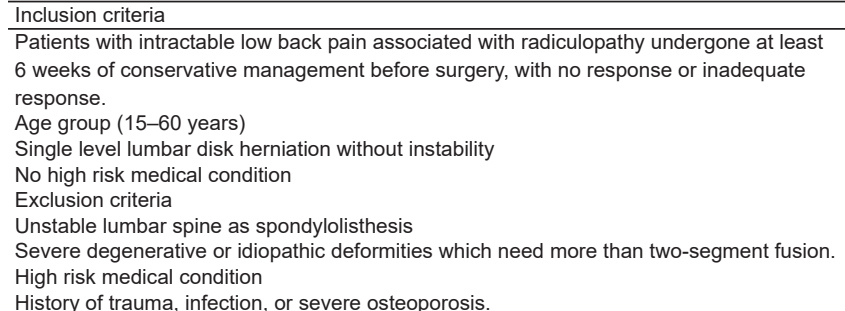

History of trauma, infection, or severe osteoporosis.

\section{Data collection and outcomes}

A full medical history was obtained including personal data as age and sex and detailed symptomatology were also acquired, including the onset, course and duration of symptoms especially back pain, lower limb pain, and the presence of any motor weakness or sphincter dysfunction.

Serial clinical and radiological examinations (CT and X-ray lumbosacral spine) were performed for both groups immediate post-operative, 3-month, 6-month, 9-month, and 1-year later for all patients.

The severity of pain in all patients was assessed using visual analog scale VAS (range 0-10), before surgery and the early post-operative data were evaluated in all patients and then patients were followed on an outpatient basis.

The accuracy of the pedicular screws was assessed using post-operative CT scans. Screws were considered to be inaccurate in case there was any medial or lateral breach of the pedicle seen in axial cuts.

\section{Interventions}

Group A

Laminectomy is done whether a hemilaminectomy or whole laminectomy, ligamentum flavum is removed by Kerrison Rongeurs, nerve root is retracted medially, and the disk is then incised by \#11 blade away from the dura and nerve root, disk is then removed by pituitary rongeurs followed by foraminotomy to free the nerve root from tension.

\section{Group B}

Pedicle screw placement was carried out before any decompression using the anatomical landmarks and also under fluoroscopic guidance, then decompression was performed and aggressive discectomy, carefully staying within the bounds of the annulus to avoid potential vascular injury. The end plates were scraped to remove the cartilaginous end plate, carefully preserving the bony end plate. Distraction was then achieved using the rods. A PEEK cage containing bone autograft from the bone removed during decompression was then inserted. Then, compression using the rods was applied to maintain the cage in position; decortication of the transverse processes was then carried out and followed by bone autograft placement between the decorticated transverse processes.

This trial was approved by the local ethical committee of the neurosurgery department of Cairo University, and all enrolled patients signed written informed consent. The trial was conducted in accordance with the protocol.

\section{Statistical methods}

Data were coded and entered using the Statistical Package for the Social Sciences (SPSS) version 26 (IBM Corp., Armonk, NY, USA). Data were summarized using mean, standard deviation, median, minimum and maximum in quantitative data, and using frequency (count) and relative frequency (percentage) for categorical data. Comparisons between quantitative variables were done using the non-parametric MannWhitney test. For comparison of serial measurements within each patient, the non-parametric Friedman test and Wilcoxon signed rank test were used. For comparing categorical data, Chi-square $\left(\chi^{2}\right)$ test was performed. Exact test was used instead when the expected frequency is $<5$. $p<0.05$ were considered as statistically significant.

\section{Results}

\section{Patient demographics}

The mean age of our patients population was 38.16 years in Group A, while in Group B, the mean was 42.76 with ages ranging from 20 to 60 years with $p=0.045$ (Table 2). 
In group $A$, females accounted for $64 \%(n=16)$ of the patients, while $36 \%$ of the patients were males $(n=9)$. In group B, females accounted for $52 \%(n=13)$ of the patients, while $48 \%$ of the patients were males $(n=12)$.

Low back pain (LBP), lower limb pain, in the form of claudication pain or sciatica was the main presenting symptoms. LBP was the most common presenting symptom, it was the main complaint in $70 \%(n=35)$ of patients and was present in $94 \%$ of our patients. Claudication pain of the lower limbs was the second most common presenting symptom. It was the main complaint in $40 \%(n=20)$ of the patients and was a symptom in $54 \%$ of our patients. Besides sciatic pain of the lower limbs was present in $44 \%(n=22)$ of patients. As well as lower limb weakness was the presenting symptom in one of our patients $(2 \%)$.

L5-S1 disk prolapse was the most common level affected in both groups with a total number of 25 patients $(50 \%)$, while L4-5 level was the second most affected level in 21 patients (42\%). Furthermore, two cases were presented with L3-4 (4\%) affection as well as L2-3 level (4\%).Secondary outcome

The mean duration of surgery was $79.60 \mathrm{~min}$ in Group A and 142.00 min in Group B with high statistical significance.

The mean intraoperative blood loss was $134.40 \mathrm{ml}$ in Group A, while the mean intraoperative blood loss in Group B was 228.00 ml with high statistical significance.

The mean post-operative hospital stay in the discectomy group was 1.60 days (ranging from 1 to 3 days) while the mean stay in the fusion group was 1.64 days (ranging from 1 to 4 days) with no statistically significant difference (Table 3).

Regarding the complications, unintended durotomy (dural tear) was encountered in $8 \%(n=2)$ of cases in Group A while encountered in only one case (4\%) in Group B with no statistically significant difference in the incidence between both groups. While two cases were complicated with superficial wound infection, one in each group and were promptly treated with antibiotics and eventually resolved.

Pedicle screw accuracy was 96\%. One case $(4 \%)$ had a screw with a medial breach and the patient was doing well with no complain and was not redirected.
Another patient had no improvement regarding the lower limb pain and even the pain increased the $2^{\text {nd }}$ day post-operative, $X$-ray was done showing cage migration $(4 \%)$ compressing the theca and was reoperated upon again for repositioning of the cage and the patient improved. Overall only one patient (4\&) in group B who needed another revision surgery.

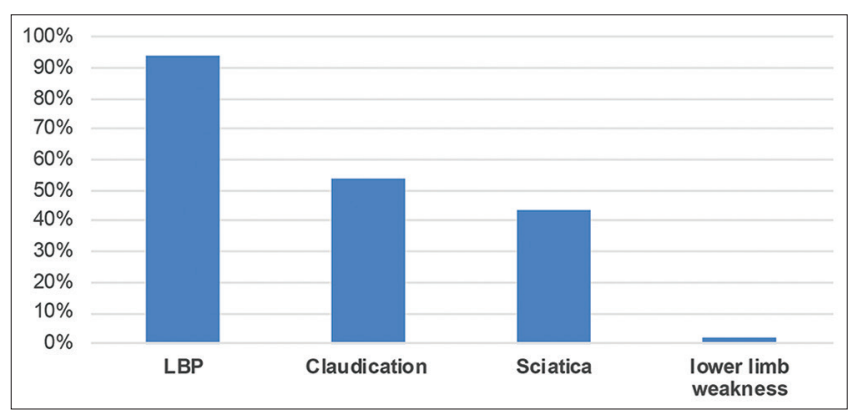

Figure 1: Bar chart showing presenting symptoms

Regarding the recurrence, two patients $(8 \%)$ in Group A complained of low back pain and lower limb pain 9 and 11 months later. MRI with and without contrast were done to both patients showing recurrence at the same level (Tables 4 and 5, Figures 1-3).

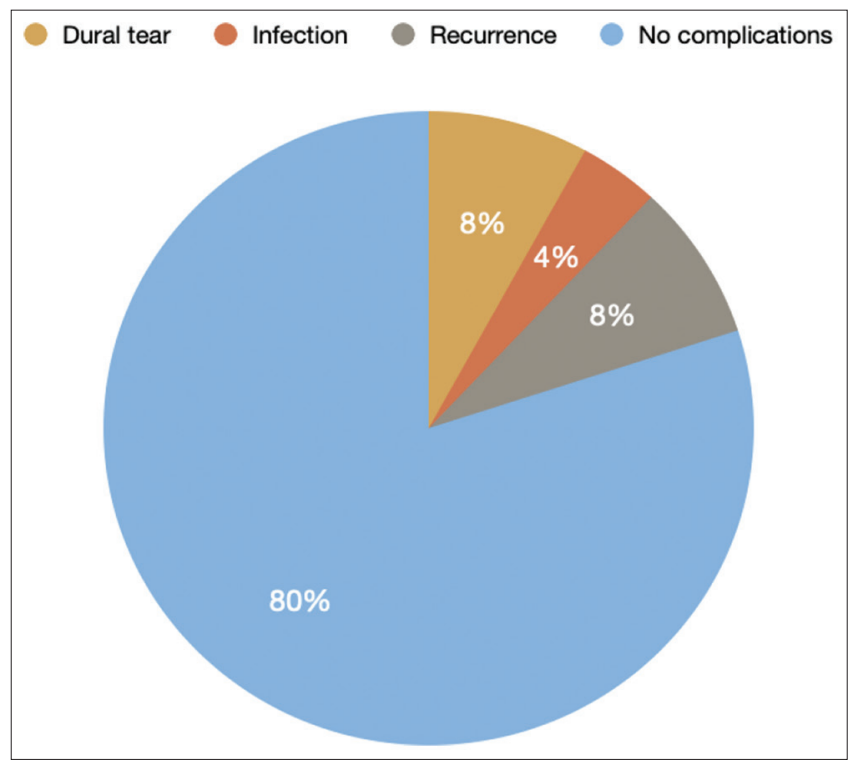

Figure 2: Incidence of complications of Group A

\section{Primary outcome}

Back pain and lower limb pain were assessed using the VAS pre and postoperatively.

Table 2: Age among both groups

\begin{tabular}{|c|c|c|c|c|c|c|c|c|c|}
\hline & \multicolumn{4}{|l|}{ Group A } & \multicolumn{4}{|l|}{ Group B } & \multirow{2}{*}{$p$-value } \\
\hline & Mean \pm S.D & Median & Minimum & Maximum & Mean \pm S.D & Median & Minimum & Maximum & \\
\hline Age & $38.16 \pm 9.01$ & 39.00 & 22.00 & 56.00 & $42.76 \pm 8.77$ & 45.00 & 25.00 & 59.00 & 0.045 \\
\hline
\end{tabular}

Table 3: Blood loss, duration os surgery, and hospital stay durations among both groups

\begin{tabular}{|c|c|c|c|c|c|c|c|c|c|}
\hline & \multicolumn{4}{|l|}{ Group A } & \multicolumn{4}{|l|}{ Group B } & \multirow[t]{2}{*}{$\mathrm{p}$-value } \\
\hline & Mean \pm S.D & Median & Minimum & Maximum & Mean \pm S.D & Median & Minimum & Maximum & \\
\hline Blood loss (ml) & $134.40 \pm 27.09$ & 130.00 & 90.00 & 170.00 & $228.00 \pm 44.72$ & 230.00 & 130.00 & 300.00 & $<0.001$ \\
\hline Duration of surgery (min) & $79.60 \pm 14.92$ & 75.00 & 60.00 & 120.00 & $142.00 \pm 24.75$ & 140.00 & 90.00 & 190.00 & $<0.001$ \\
\hline hospital stay (days) & $1.60 \pm 0.71$ & 1.00 & 1.00 & 3.00 & $1.64 \pm 0.81$ & 1.00 & 1.00 & 4.00 & 0.974 \\
\hline
\end{tabular}




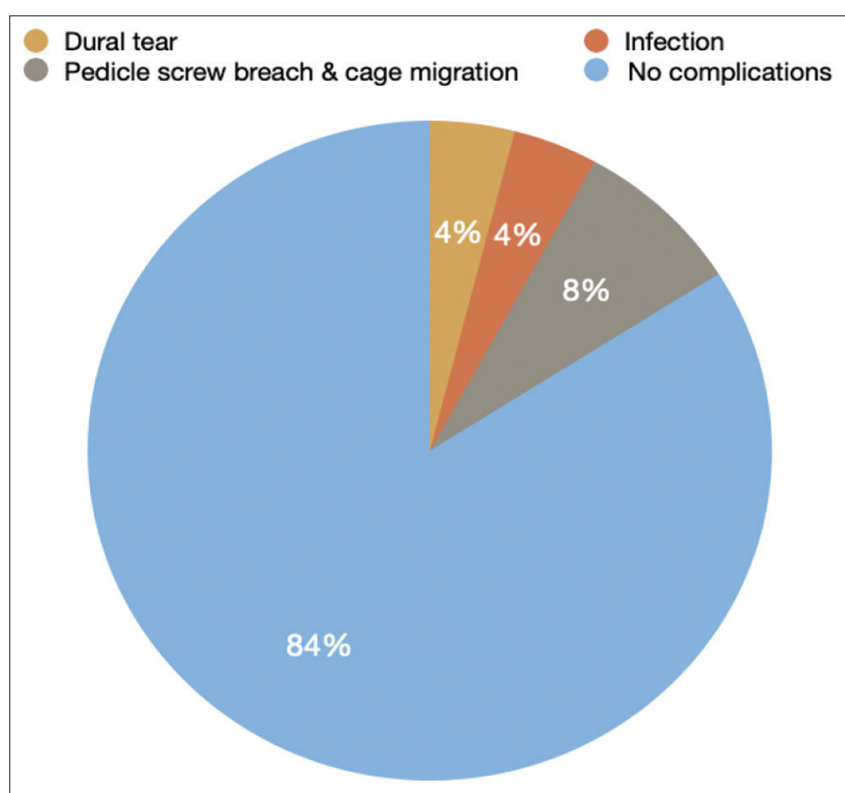

Figure 3: Incidence of complications of Group B

Back pain was assessed postoperatively in the $2^{\text {nd }}$ day post-operative then 3-month, 6-month, 9-month, and 1-year later. The mean VAS of back pain preoperatively was 5.28 in the discectomy group and 5.56 in the fusion group. Post-operative day 2 showed improvement in the VAS with mean values of 3.28 and 2.88 in the discectomy and fusion groups, respectively, with no statistically significant value as well as 3 months later. At 6-month post-operative, the mean values were 1.84 and 0.72 favoring the fusion group ( $p=0.004)$. At 9 -month post-operative, the mean values were 1.92 and 0.60 favoring the fusion group. One-year showed improvement of the VAS in Group B with mean VAS 1.32 and 0.40 in the discectomy and fusion groups, respectively, with statistically significant difference between both groups.

Table 4: Complication rates among both groups

\begin{tabular}{|c|c|c|c|c|}
\hline & \multicolumn{2}{|c|}{ Group A } & \multicolumn{2}{|c|}{ Group B } \\
\hline & Count & $\%$ & Count & $\%$ \\
\hline \multicolumn{5}{|l|}{ Complications } \\
\hline Yes & 5 & 20.0 & 4 & 16.0 \\
\hline No & 20 & 80.0 & 21 & 84.0 \\
\hline Cage migration & 0 & 0.0 & 1 & 4.0 \\
\hline Dural tear & 2 & 8.0 & 1 & 4.0 \\
\hline Infection & 1 & 4.0 & 1 & 4.0 \\
\hline Pedicle screw breach & 0 & 0.0 & 1 & 4.0 \\
\hline Recurrence & 2 & 8.0 & 0 & 0.0 \\
\hline
\end{tabular}

Lower limb pain showed marked improvement in the VAS comparing the pre-operative and the post-operative results. However, there were no statistically significant differences between the two groups.

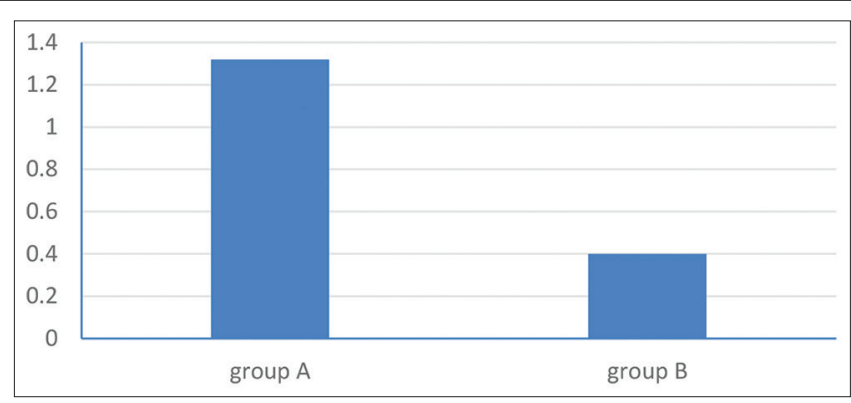

Figure 4: Bar chart showing back pain VAS post-operative at 1 year

The mean duration of symptoms before surgery was $14.93 \pm 10.523$ months and ranged from 2 to 52 months (Table 5 and Figures 4-10).

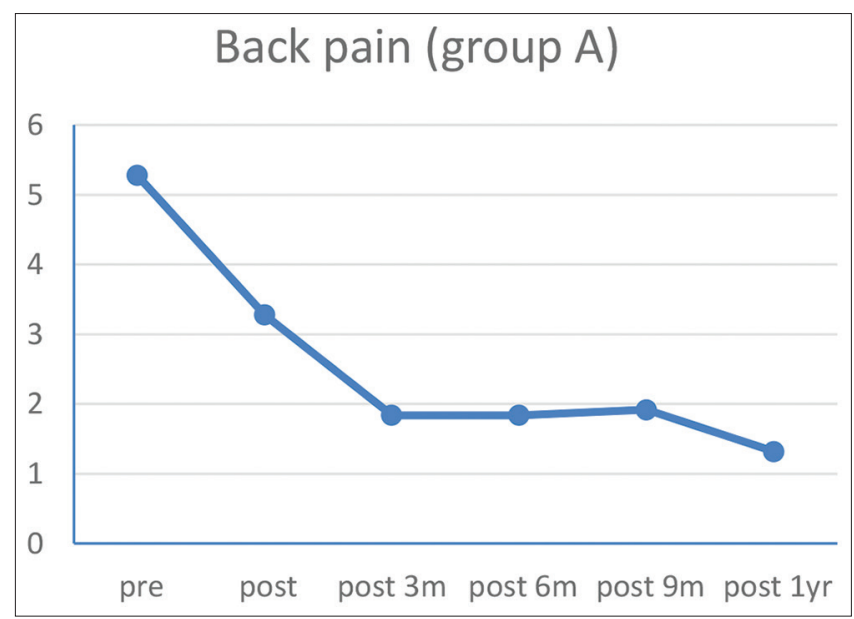

Figure 5: Graph showing back pain improvement throughout the follow-up period

\section{Discussion}

Lumbar discectomy is the most commonly performed procedure for the treatment of radiculopathy caused by lumbar disk herniation [7].

Patients who are unable to tolerate the disability associated with lumbar disk herniation in the short-term, or those with symptoms refractory to conservative therapy, may choose a surgical intervention. For patients treated with lumbar discectomy, reoperation (i.e., subsequent lumbar discectomy, laminectomy, or fusion) has been reported to occur at rates ranging from $5 \%$ to $24 \%$ [8]

Patients may experience back pain after an open lumbar discectomy for a LDH. Several studies

Table 5: Back pain VAS among both groups throughout the follow-up period

\begin{tabular}{|c|c|c|c|c|c|c|c|c|c|}
\hline & \multicolumn{4}{|c|}{ Group A } & \multicolumn{4}{|c|}{ Group B } & \multirow[t]{2}{*}{$p$-value } \\
\hline & Mean \pm S.D & Median & Minimum & Maximum & Mean \pm S.D & Median & Minimum & Maximum & \\
\hline \multicolumn{10}{|l|}{ Back pain } \\
\hline Pre & $5.28 \pm 1.46$ & 6.00 & 2.00 & 8.00 & $5.56 \pm 1.26$ & 6.00 & 3.00 & 8.00 & 0.652 \\
\hline Post & $3.28 \pm 1.28$ & 3.00 & 1.00 & 6.00 & 2.881 .83 & 2.00 & 1.00 & 8.00 & 0.091 \\
\hline Back pain post 3-month & $1.84 \pm 1.11$ & 2.00 & 0.00 & 4.00 & $1.40 \pm 0.91$ & 1.00 & 0.00 & 3.00 & 0.180 \\
\hline Back pain post 6-month & $1.84 \pm 1.52$ & 2.00 & 0.00 & 5.00 & $0.72 \pm 0.84$ & 1.00 & 0.00 & 3.00 & 0.004 \\
\hline Back pain post 9-month & $1.92 \pm 2.22$ & 1.00 & 0.00 & 8.00 & $0.60 \pm 0.76$ & 0.00 & 0.00 & 3.00 & 0.010 \\
\hline Back pain post 1 -year & $1.32 \pm 1.25$ & 1.00 & 0.00 & 4.00 & $0.40 \pm 0.50$ & 0.00 & 0.00 & 1.00 & 0.004 \\
\hline
\end{tabular}




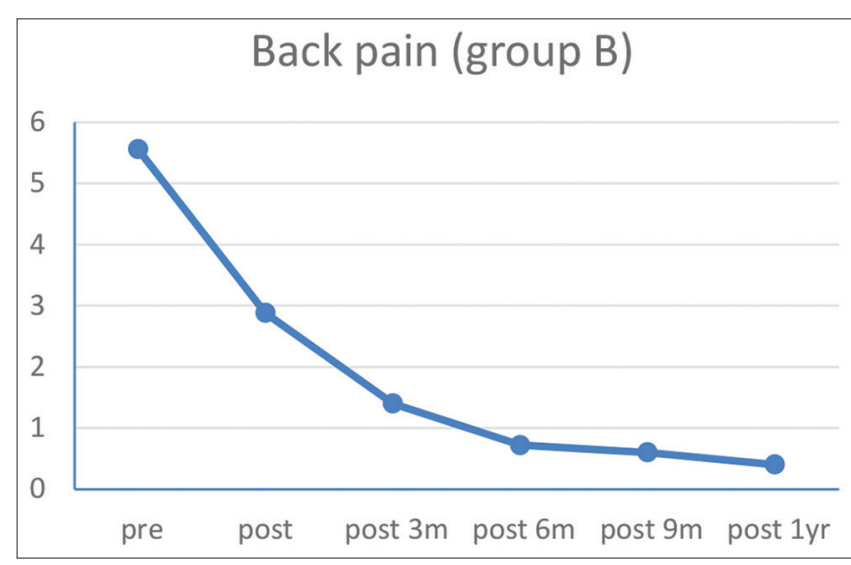

Figure 6: Graph showing back pain improvement throughout the follow-up period

have observed long-term post-operative changes of the lumbar spine in patients who had undergone discectomy for a LDH. Yorimitsu et al. [9] reported a $25 \%$ loss of the disk height 10 years after a discectomy, and Barth et al. [10] reported a significant increase in endplate degeneration after discectomies. However, long-term follow-up studies of the relationship between these radiological findings and clinical outcomes are rare [9], [10].

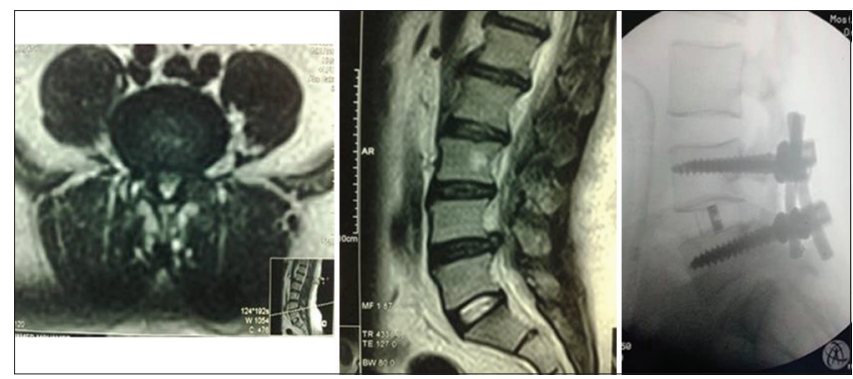

Figure 7: Pre-operative sagittal and axial T2-weighted MRI images and post-operative lateral $X$-ray

Our results showed minimal difference between the study groups regarding age, with a mean age of 38.16 years among Group $A$ and 42.76 years among Group B. Besides females accounted for the majority (64\%) of our patients in Group A as well as $(52 \%)$ in Group B. Moreover, the most commonly affected level is L5-S1 level (50\%), followed by L4-5 (42\%).

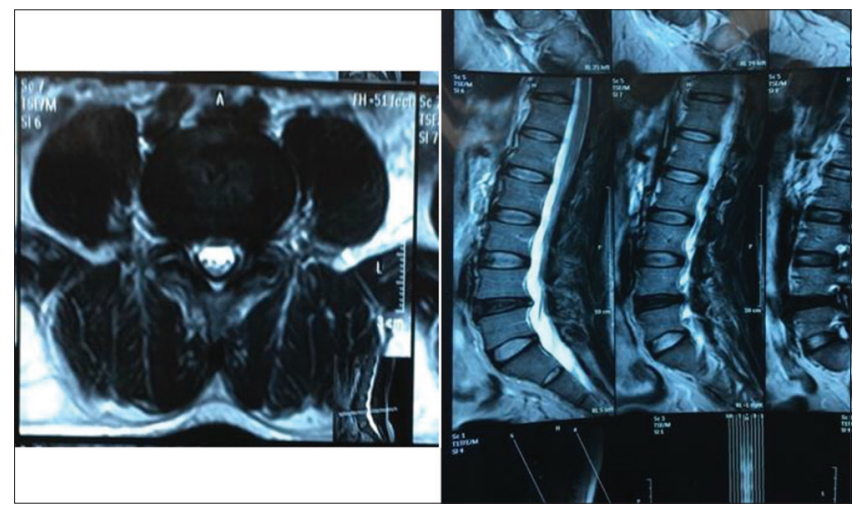

Figure 8: Pre-operative sagittal and axial T2-weighted MRI images showing L4-5 disk prolapse

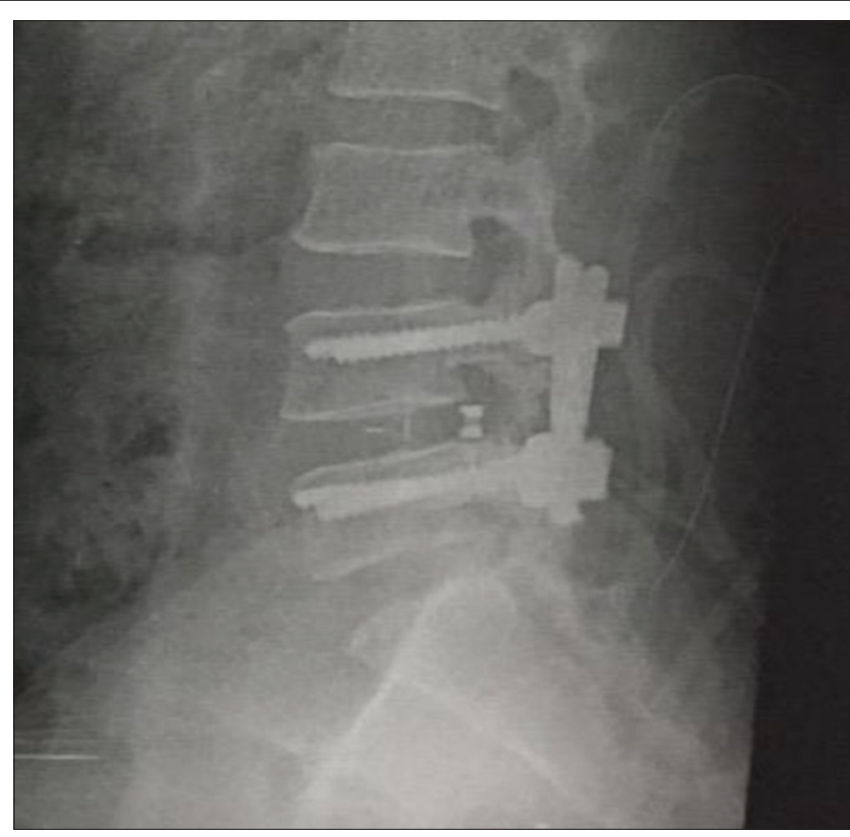

Figure 9: Post-operative lateral $X$-ray image showing migrating cage encroaching on the canal

Putzier et al. showed similar results with a mean age of 38.5 years, with female predominance and

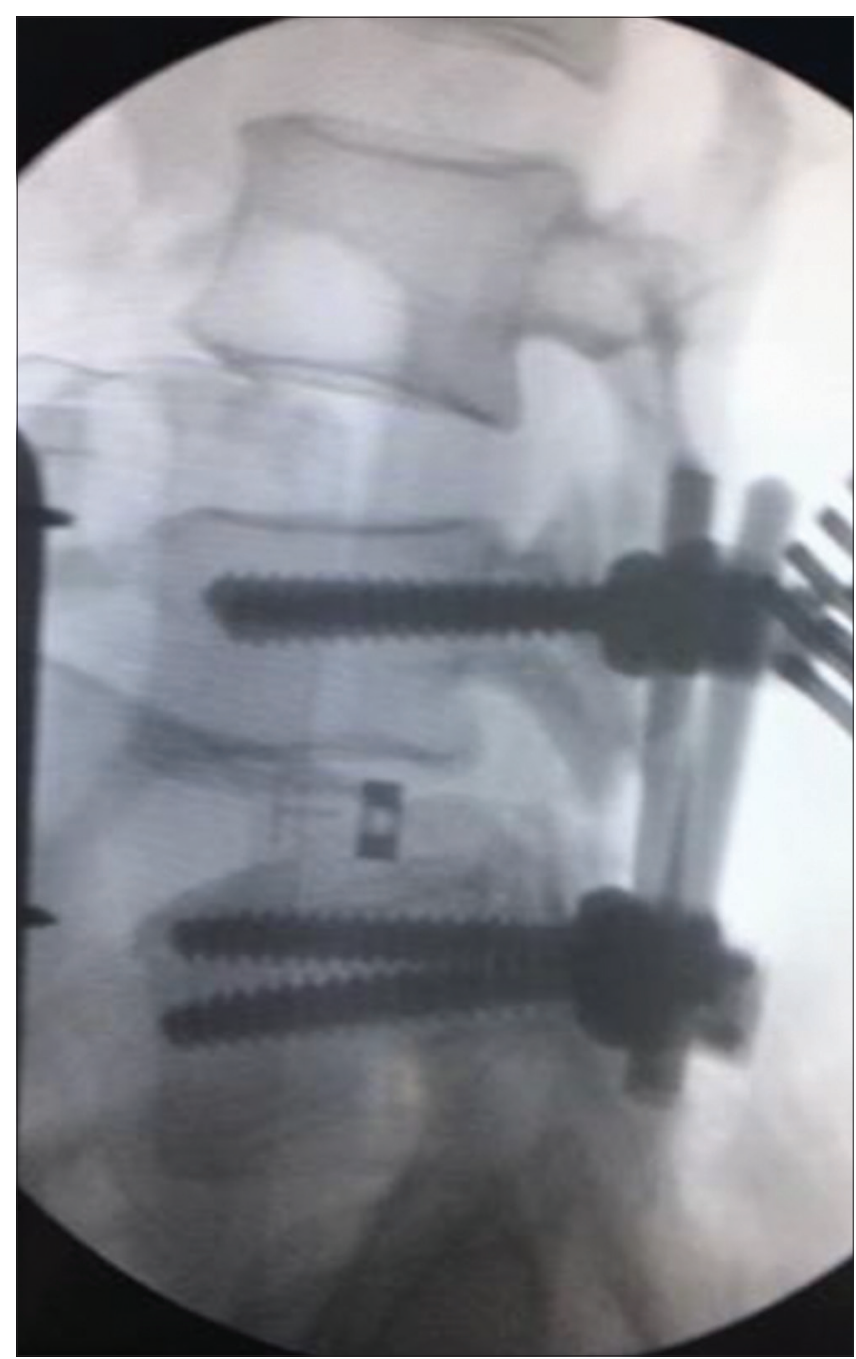

Figure 10: Post-operative lateral X-ray image showing cage position after revision surgery 
the L5-S1 level (50\%), followed by L4-5 were the most common affected levels as well [11].

The duration of clinical symptoms had a wide range, from 2 to 43 months, with a mean duration of 19.93 months. The main presenting symptoms included low back pain, lower limb pain in the form of claudication or sciatic pain. Low back pain was the most common symptom, affecting $94 \%$ of our patients, followed by claudication pain which affected $54 \%$ of patients and sciatic pain of the lower limbs which was present in $44 \%$ of patients, while lower limb weakness affected only one patient $(2 \%)$ and was in the form of foot drop. Mura et al. reported similar results, with back pain being the most common presenting symptom of his patients [12].

Regarding the complications, unintended durotomy (dural tear) was encountered in 2 cases in Group A while encountered in only one in Group B with no statistically significant difference in the incidence between both groups.

Other complications included superficial wound infection in one case in each group that was promptly treated with antibiotics according to culture and sensitivity and eventually resolved.

In our cases, pedicle screws accuracy was $96 \%$. Only one case had a screw with a medial breach and the patient was doing well. Overall, there were no neurological symptoms related to screw misplacement and none required to be repositioned. Humphreys et al. also reported similar results in his study [13].

Another patient had no improvement regarding the lower limb pain and even the pain increased the $2^{\text {nd }}$ day post-operative due to cage migration. Cage was compressing the theca and needed a corrective surgery to reposition it and the patient improved.

Regarding the recurrence, two patients $(8 \%)$ in Group A complained of low back pain and lower limb pain 9 and 11 months later. MRI with and without contrast were done to both patients showing recurrence at the same level.

One of them received medical treatment with improvement of his condition and the other patient did not improve and was re operated upon for discectomy and interbody fusion with bilateral pedicular screw fixation with improvement of condition later on.

Satoh et al. stated that he had recurrent disk herniation at the same level as initial surgery in 10 patients and at another level in 4 patients. He indicated that residual back pain and recurrent disk herniation were important factors affecting long-term results of discectomy alone [14].

Heindel et al. reported that $12.2 \%$ of patients receiving single-level discectomy underwent reoperation within 4 years, and of patients who underwent re-exploration discectomy, $38.4 \%$ of them progressed to a lumbar fusion [15].
II-Nam et al. had a reoperation rate of $13.4 \%$ during a mean follow-up period of 15.3 years [16].

Our study had a reoperation rate of $4 \%$ in the conventional discectomy group during a 1-year follow-up, several studies have reported rates of reoperation of $6 \%-17 \%$ during their long-term follow-up periods [17].

The mean post-operative hospital stay in the discectomy group was 1.60 days (ranging from 1 to 3 days), while the mean stay in the fusion group was 1.64 days (ranging from 1 to 4 days).

Humphrey et al. reported that the mean hospital stay for his patients was 3.5 days, and this was much longer than our patient's hospital stay [13].

Regarding the primary outcome, the pain assessment was an integral part of our study. We used the visual analog scale (VAS) for our pain assessment. Our aim was to compare the pre-operative and postoperative back pain and lower limb pain scores, so as to determine if the fusion group had better post-operative pain profile.

The mean VAS of back pain preoperatively was 5.28 in the discectomy group and 5.56 in the fusion group. At 6 months post-operative, the mean values were 1.84 and 0.72 favoring the fusion group. Moreover, at 9-month post-operative, the mean values were 1.92 and 0.60 favoring the fusion group. Moreover, at 1 year showed marked improvement of the VAS in the fusion group with mean VAS 0.40 compared to the discectomy group with a mean of 1.32 with statistically significant difference between both groups. Both groups were found to have significant improvement in VAS for back pain at 1 year when compared to the pre-operative VAS values with the fusion group dominating regarding more improvement at all intervals especially at 9 months and 1 year period.

II-Nam et al. proved in his study that included 79 patients operated upon by standard open discectomy for lumbar disk herniation that the VAS scores for back or leg pain and the ODI scores were low in the $1^{\text {st }} 10$-year post-operative and increased slightly over time through the 15-20-year follow-up correlating with increase in radiological findings of spinal degeneration or instability. It has been suggested that these progressive degeneration in radiological findings make it more likely that clinical outcomes for these patients are the result of spinal degeneration [16].

Furthermore, Mura et al. demonstrated a statistically significant improvement in the 12- and 24-month mean pain scores and 24-month mean role physical scores compared with the pre-operative scores on the same scales through achieving fusion of the lumbar spine to obtain a primary solid arthrodesis thus to alleviate pain [12].

Furthermore, Young et al. demonstrated in his study that the satisfactory rate of backache was $68 \%$ in 
the fusion group and $48 \%$ in the non-fusion group and that of sciatica was $74 \%$ and $53 \%$, respectively [17].

Vaughan et al. as well reported that the fusion group (posterolateral fusion) had significantly better results than the non-fusion group $(85 \%$ satisfactory results vs. 39\%) [18].

Lower limb pain showed marked improvement in the VAS comparing the pre-operative and the postoperative results among all our patients. The mean pre-operative VAS was 5.96 in the discectomy group and 7.08 in the classic group. Postoperatively at one year, the mean VAS improved to 0.88 and 0.56 , respectively. However, there was no statistically significant difference between the degrees of improvement in both groups.

II-Nam et al. found in his study marked improvement in the VAS score for the lower limb pain whom were operated for open lumbar discectomy over time, unlike the VAS score for the back pain that improved for 10 years and then started to worsen. However, it remains unclear whether worsening was due to spinal degeneration progressing with the natural aging process or was the result of accelerated degeneration after an OLD [16].

Takeshima et al. argued in his study that the reduction in low back pain after surgery was greater in the fusion group and that no significant differences in other subjective symptoms (leg pain, ability to walk) or objective findings (straight leg raising, sensory abnormality, and manual muscle testing) were found between the fusion and non-fusion groups [19].

\section{Study limitation}

Among the limitations of this study is the lack of randomization of the patients. As well as segmental and global sagittal balance measures were not compared in this study. Larger studies with longer follow-up periods are required for proper evaluation of the best method of LDH treatment.

\section{Conclusion}

Clinical outcome was excellent in both groups. The reduction in low back pain after surgery was greater in the fusion group $(p<0.05)$. The rate of recurrent disk herniation at the surgical level in the nonfusion group was higher, but intraoperative blood loss, operation time, length of hospital stay, and total cost of procedure were all less in the patients undergoing discectomy alone. Spinal fusion can settle these problems and attain a better and more durable outcome than discectomy alone.

\section{References}

1. Cowperthwaite MC, van den Hout WB, Webb KM. The impact of early recovery on long-term outcomes in a cohort of patients undergoing prolonged non-operative treatment for lumbar disc herniation: clinical article. J Neurosurg Spine. 2013;19(3):301-6. https://doi.org/10.3171/2013.5.spine12992 PMid:23808581

2. Sloan TJ, Walsh DA. Explanatory and diagnostic labels and perceived prognosis in chronic low back pain. Spine (Phila $\mathrm{Pa}$ 1976) 2010;35(21):E1120-5. https://doi.org/10.1097/ brs.0b013e3181e089a9 PMid:20838269

3. Marshall LW, McGill SM. The role of axial torque in disc herniation. Clin Biomech (Bristol, Avon). 2010;25(1):6-9. PMid:19815318

4. Iwao S, Kazuo Y, Noboru H, Tetsuo O, Takeshi F, Yoshikawa H, et al. Indication of posterior lumbar interbody fusion for lumbar disc herniation. J Spinal Disord Tech. 2006;19:104-8. https://doi. org/10.1097/01.bsd.0000180991.98751.95 PMid:16760783

5. Stonecipher T, Wright S. Posterior lumbar interbody fusion with facet-screw fixation. Spine. 1989;14(4):468-71. https://doi. org/10.1097/00007632-198904000-00026 PMid:2718053

6. Cloward RB. The treatment of ruptured intervertebral discs by vertebral body fusion. I. Indications, operative technique, after care. J Neurosurg. 1953;10(2):154-68. https://doi.org/10.3171/ jns.1953.10.2.0154

PMid:13035484

7. Deyo RA, Weinstein JN. Low back pain. N Engl J Med. 2001;344(5):363-70.

PMid:11172169

8. Weinstein JN, Tosteson TD, Lurie JD, Tosteson AN, Hanscom B, Skinner JS, et al. Surgical vs nonoperative treatment for lumbar disk herniation: The spine patient outcomes research trial (SPORT): A randomized trial. JAMA. 2006;296(20):2441-50. https://doi.org/10.1001/jama.296.20.2441

PMid: 17119140

9. Yorimitsu E, Chiba K, Toyama Y, Hirabayashi K. Longterm outcomes of standard discectomy for lumbar disc herniation: A follow-up study of more than 10 years. Spine (Phila Pa 1976). 2001;26(6):652-57. https://doi. org/10.1097/00007632-200103150-00019

PMid: 11246379

10. Barth M, Diepers M, Weiss $C$, Thomé $C$. Two-year outcome after lumbar microdiscectomy versus microscopic sequestrectomy: Part 2: Radiographic evaluation and correlation with clinical outcome. Spine. 2008;33(3):273-9. https://doi.org/10.1097/ brs.0b013e31816201a6

PMid: 18303459

11. Putzier M, Schneider SV, Funk JF, Tohtz SW, Perka C. The surgical treatment of the lumbar disc prolapse: Nucleotomy with additional transpedicular dynamic stabilization versus nucleotomy alone. Spine. 2005;30(5):E109-14. https://doi. org/10.1097/01.brs.0000154630.79887.ef

PMid: 15738772

12. Mura PP, Costaglioli M, Piredda M, Caboni S, Casula S. TLIF for symptomatic disc degeneration: A retrospective study of 100 patients. Eur Spine J. 2011;20(1):57-60. https://doi.org/10.1007/ s00586-011-1761-2

PMid:21461695

13. Humphreys SC, Hodges SD, Patwardhan AG Eck JC, Murphy RB, Covington LA. Comparison of 
posterior and transforaminal approaches to lumbar interbody fusion. Spine. 2001;26(5):567-71. https://doi. org/10.1097/00007632-200103010-00023

14. Satoh I, Kazuo Y, Noboru H, Tetsuo O, Takeshi F, Yoshikawa H, et al. Indication of posterior lumbar interbody fusion for lumbar disc herniation. J Spinal Disord Tech. 2006;19(2):104-8. https:// doi.org/10.1097/01.bsd.0000180991.98751.95

15. Heindel P, Tuchman A, Hsieh PC, Pham MH, D'Oro A, Patel NN et al. Reoperation rates after single-level lumbar discectomy. Spine. 2017;42(8):E496-501. https://doi.org/10.1097/ brs. 0000000000001855

PMid:27548580

16. II-Nam S, Kim YH, Ha KY. Long-term clinical outcomes and radiological findings and their correlation with each other after standard open discectomy for lumbar disc herniation. J Neurosurg
Spine. 2015;22(2):179-84. https://doi.org/10.3171/2014.10. spine 131126

17. Young HH, Love GJ. End results of removal of protruded lumbar intervertebral discs with and without fusion. Am Acad Orthop Surg Inst Course Lecture. 1959;16:213-6.

18. Vaughan PA, Malcolm BW, Maistelli GL. Results of L4-L5 disc excisionaloneversusdiscexcisionandfusion. Spine. 1988;13:6905. https://doi.org/10.1097/00007632-198813060-00018 PMid:3175759

19. Takeshima T, Kambara K, Miyata S, Ueda Y, Tamai S. Clinical and radiographic evaluation of disc excision for lumbar disc herniation with and without posterolateral fusion. Spine. 2000;25(4):450-6. https://doi.org/10.1097/00007632-200002150-00010 PMid:10707390 